\title{
Memorable Experiences in Research
}

\author{
Distinguished scientists present at the scientific session \\ held in connection with the formal opening of The Charles \\ H. Best Institute were each asked in turn by Doctor Best \\ "Which of your scientific investigations has given you \\ the most satisfaction and pleasure?" Their replies follow.
}

\section{E. D. Adrian, Ph.D., President of the Royal Society, London}

It is a very great honour to take part in this presentation. I'm not really very clear what you would like me to do, but I thought it would be best merely to describe one day's experiment which was, to me, an exceedingly enjoyable experience. The pleasure came not so much from doing the work as from realizing suddenly that I had found a way of doing a great deal more. I'm afraid that the argument will be mainly concerned with the techniques of electro-physiology, but it does illustrate the way things go sometimes without the need for any excessive hard work or excessive thought.

It was in the early 20's. I had taken up electro-physiological research on the central nervous system and had spent a great deal of time making string galvanometer records of action currents in the hope of being able to find out exactly what was coming down the nerve fibres when the muscle contracted. We knew then that nerves sent down nerve impulses as signals, but we didn't know anything about the way in which the impulses would follow one another. We didn't know whether they came at a high frequency, or at a steady frequency. We didn't know whether the frequency varied or not. In fact, we didn't know at all how the nervous signals were controlled. Alexander Forbes had been working with me in Cambridge and I had learned a great deal from him about string galvanometers and about mammalian preparations, but the experiments I had started became more and more unprofitable. You know the sort of thing that happens- they became more and more complicated and the evidence more indirect, and after a time it was quite clear that I was getting nowhere at all. But it was fairly clear at that time that the valve amplifier was going to make it very much easier to record action potentials, particularly very small ones, and there had been various descriptions of valve amplifying arrangements. In particular, Gasser and Newcomer had used a three-stage one to record action potentials in the phrenic nerve. I had rigged up a single valve one, but it wasn't much good, so having decided that I was getting nowhere, I wrote to Gasser for the details of the arrangement he was using for the phrenic. He was then beginning his studies with the cathode-ray oscillograph on the action potentials of nerve fibres of different sizes, but he gave me a full description of the amplifier that he and Newcomer had used, and I built one to much the same pattern. I knew very little about it and was rather afraid of all the complications in it. When it was ready, I decided to test it using the capillary electrometer which was in the laboratory, built by Keith Lucas about fifteen years before. I used the capillary electrometer because, although it wasn't as sensitive as the string galvanometer, it had the great advantage of being more foolproof in that it wasn't so easy to break the string if you overloaded it. The amplifier had to be treated with great respect, as in those days the valves were terribly microphonic. The arrangement I had gave a magnification of about 2000 , so I set up a pair of 
non-polarizable electrodes in a shielded chamber, and put the normal accompaniment of physiological research, the frog's nerve-muscle preparation, on the electrodes, to see whether I could get a steady base line. Well, I was distressed, but not very greatly surprised, to find that the base line wasn't a bit steady. It was oscillating rapidly all the time. As soon as the circuit was open there was this constant rapid oscillation going on and I naturally suspected that I was picking up an artifact from somewhere and that I should have to pull the whole apparatus down and stick it all together again and go on for another month or so, getting no results.

I began re-adjusting the apparatus, and then I found that sometimes the oscillation was there (it was a fine, rapid affair) and sometimes the base line was quite steady. There was a ray of hope, and after trying various arrangements, I found that this little oscillation was only there when the muscle was hanging down quite freely, from the knee joint of the frog's nerve-muscle preparation. If the muscle was supported on a glass plate there was no oscillation at all and the base line was quite steady. The explanation suddenly dawned on me, and that was a time when I was very pleased indeed. A stretched muscle, a muscle hanging under its own weight, ought, if you come to think of it, to be sending sensory impulses up the nerves coming from the muscle spindles, signalling the stretch on the muscle. When you relax the stretched muscle, when you support it, those impulses ought to cease.

I don't think it took more than an hour or so to show that that was what the little oscillations were. I was able to make photographic records of them, and within about a week I was nearly certain that many of these oscillations were action potentials coming up sensory fibres in the nerve, and what was more, that many of them came from single nerve fibres and that by some extension of the technique it ought to be possible to find out exactly what was happening in single nerve fibres when the sense organs attached to them were stimulated.

That particular day's work, I think, had all the elements that one could wish for. The new apparatus seemed to be misbehaving very badly indeed, and I suddenly found that it was behaving so well that it was opening up an entire new range of data. I'd been bogged down in a series of very unprofitable experiments and here suddenly was the prospect of getting direct evidence instead of indirect, and direct evidence about all sorts of problems which I had set aside as outside the range of the techniques that one could use. The other point about it was that, as I said, it didn't involve any particular hard work, or any particular intelligence on my part. It was one of those things which sometimes just happens in a laboratory if you stick apparatus together and see what results you get.

\section{Detlev W. Bronk, M.D., President, Rockefeller Institute for Medical Research}

Because I was a construction engineer before I was a physiologist, it gives me a special and nostalgic pleasure to speak to the accompaniment of constructive sounds of building still going forward and in this auditorium hastened to completion for this occasion. This is symbolic of the creative energy of Charles Best.

I have found it difficult to choose from among the scientific adventures that have comprised a happy and a satisfying life for me. I have therefore chosen to speak of a sequence of experiences. I have done so with the hope that my remarks will have the simple value of revealing how research may be directed by the unplanned events of life. For I believe, as Sir Lionel Whitby said yesterday afternoon, that the course of research is directed in no small part by subtle unplanned influences and undirected curiosity. My experiences have persuaded me that the spirit of research is a fundamental motive in human life.

I had the good fortune to be educated as an electrical engineer with an exciting interlude as a naval aviator. But when I came to the practice of my profession, I found that I was more interested in the nature of matter and physical phenomena than in the application of such knowledge to the solution of industrial problems. This led me to graduate work in physics.

I doubt whether any young man of my generation was less interested in the nature of biological processes than I, or so poorly informed. My indifference to such elements of a normal curiosity was shaken by an accidental injury to one of my eyes which aroused me to admiring 
wonder regarding the mechanisms of the human body. They excited my engineering instincts. Thus I began my adventures in physiology at the University of Michigan.

Because I had a father who had spent four happy years in graduate study on the continent of Europe, I had the feeling that preparation for an academic career was incomplete without such a supplement to an American foundation. But English literature had fostered the development of sentimental ties which pulled me more to England than to my father's European Alma Maters, and especially to Cambridge, as did pictures of its architectural beauty.

The appeal of Cambridge was greatly strengthened by the exciting experiments which have been described this morning by Professor Adrian. For not only was the spectacular significance of those studies of nerve messages readily apparent to even the beginner in physiology, but they also involved the use of electronic amplifiers, and it happened that a few years before I had had the privilege of giving one of the early graduate courses in electronics because the professor in charge had gone on sabbatical leave. So I was drawn to Adrian's work by the feeling that my excursion into physiology would be aided by special knowledge in another field. The threads of circumstance were beginning to be woven into a satisfying fabric of research.

When I arrived at Cambridge to begin the happy associations and friendships I have now enjoyed for a quarter century, the first phase of Adrian's work on sensory receptors was drawing to a close. It was then that he suggested we investigate the possibility of recording the discharge of impulses from single motor nerve cells. For this, the rhythmically excited fibers of the phrenic nerve seemed ideal, for we thus avoided the hazards of artifacts from electrical stimuli which plagued the amplifiers of those early days. One more thread led to a useful past, for my first research in physiology had been guided by Gesell to the excitation of the respiratory center.

Some years later, when I was at the University of Pennsylvania, I happened to receive from Pennsylvania State College an invitation to give the Joseph Priestley lectures of that institution. I decided to describe the work that Adrian and I had done and the things that I had gone on doing in the Johnson Foundation. But it occurred to me that I should be prepared to make some appropriate and related remarks about Joseph Priestley's interest in the possible physiological effects of oxygen at the beginning of my lecture series. This and my previous work on the discharge of impulses in the phrenic and intercostal nerves aroused some latent interest in the oxidative metabolism of nerves and its relation to their rhythmic action.

But it was by chance that some advertising literature describing equipment for polarographic determinations came to my laboratory table. As I casually studied this circular, it occurrèd to me that polarography might be a means for measuring the oxygen consumption in peripheral nerve and in the central nervous system. If that could be done, thought I, I should have appropriate and significant material for a series of lectures in memory of Joseph Priestley. That was the beginning of the investigations Brink and I and our colleagues have directed to the electrochemical determination of oxygen concentrations in the nervous system with a high degree of spatial and temporal localization and accuracy.

That was in the dark days of 1939 and 1940. I was becoming much distressed by American colleagues who seemed to me to be inadequately aware of the great danger we were facing and of our responsibility with you of the Empire for our common defense. I was, I suppose, in part moved to this concern because of the happy days I had had in the laboratories of Adrian at Cambridge and Hill at London. Be that as it may, I desperately wished to do something useful to withstand the Nazi's perilous assault. Because of our oxygen studies, I began to think about the special requirements of submariners and aviators for oxygen. We began to shift the use of our polarography methods for studying oxygen concentration in the nervous system and our study of motor and sensory nerve impulses to their military implications and applications.

Not long after that, I was reminded by the United States Air Force that I had been an aviator before I became a physiologist and it was now my responsibility to join in their operations. This I gladly did. I soon realized with satisfaction that the needs of those urgent days did not dissociate me completely from my recent scientific interests. For Adrian's experiments, which first aroused my admiration in nervous mechanisms, dealt with the effects of gravity and tension on the organism. In the case of aviators, impulses were initiated by the high forces developed by internal combustion engines and this gave rise for the necessity of anti-acceleration suits. The reason why it became necessary to develop equipment which would adequately supply oxygen to our aviators who flew their missions high over the Nazis' European fortress was because there was not enough oxygen present at those high altitudes to keep alive the nerve cells which Adrian and I had been studying. So, 
too, were the nervous mechanisms of vision intimately concerned with night flying techniques and the nerve impulses from the vestibular apparatus were related to problems of instrument flying and the early instruction of fliers.

Throughout those four rewarding years which marked the end of one era of my research and the beginning of another, I had the gratification of seeing adventures in aviation, engineering, physics, nerve physiology and biochemistry converge in one undertaking.

The lessons I would draw are these. To follow one's curiosity is more satisfying than to follow the planned direction of another, for no one can chart the course of exploration through unexplored territories of knowledge. To specialize too early and too much denies one the adequate preparation for unanticipated adventures in science where there are no natural boundaries or departments of knowledge.

Charles Best has been thanked for many things. $\mathrm{He}$ has been lauded in terms he well deserves. I would add my gratitude for his encouragement and his willingness to listen, and to have his students listen, to the enthusiasms of one who had ceased to be an engineer and physicist and had not yet qualified as a physiologist.

\section{Sir Henry Dale, Past President of the Royal Society, London}

Like those who preceded me in this series, and I suppose like those who will follow, I felt a bit puzzled in considering how I should treat this attractive invitation, to say something about that one of my scientific investigations which has given me the most satisfaction and pleasure. You see, there are all kinds of satisfaction and pleasure which one can get out of scientific work. One of the very greatest satisfactions is that of working in happy comradeship with good colleagues. On those lines, I should be tempted to choose, particularly in this connection, the opportunity which I had to work with Charlie Best and Joseph Hoet back in 1925-1926. It certainly gave me much satisfaction and pleasure; but I'm not going to choose it for this occasion, because, for one thing, we've naturally heard a good deal during the past two days about insulin and work on insulin; and another reason is that I never considered that to be one of my scientific investigations.

My friends will remember that I was taking an interest in what they were doing, and occasionally lending a hand in a particular technical operation; but I had always thought of it as essentially their work, and nothing has touched me more, in all my experience, than to have them come to me, when it was done, and insist that I should let my name appear on what I had regarded as a paper of theirs. This I had never intended. It is an easy thing, you know, for a senior to make a generous gesture to his juniors, in that sort of position. I know from my own memory, however, that it is not at all so easy for the juniors to be generous to a senior, and to have their credit diluted by introducing the name of a senior man.
Well, I resisted as long as I could, until finally they said, "We are not going to publish it unless you put your name on it with ours."

That's a very, very happy memory; but I think that, for the present purpose $I$ ought to concentrate on a different experience, and one which has just been brought rather vividly to my mind and has given me a great deal of satisfaction in retrospect; because I've only just come from a very lively and interesting symposium in Philadelphia, in which contributors from a number of different countries presented and discussed, greatly to my interest, even my excitement, new evidence bearing upon what the organizers of the symposium called "neurohumoral transmission." That is not a word that I pronounce very easily. I've always called it, rather more briefly and simply, "chemical transmission,"-the transmission of the effects of nerve impulses across synapses of various kinds, and other neuro-effector junctions, by the liberation of stimulating chemical substances. I feel bound then to choose, for my topic, that observation of my own which appears to be having the most vigorous development in other hands at the present time, namely, my observations on acetyl-choline, which revealed its intense and evanescent parasympathomimetic actions on various forms of involuntary muscles and glands, and then on autonomic ganglia and voluntary muscles.

I didn't discover the action of acetyl-choline. That was discovered by another friend of mine, the late Reid Hunt, whom I first met when we were both young men together, working in Paul Ehrlich's laboratory in Frankfurt. For years I hadn't thought very much about an ob- 
servation which he had made in 1905-1906, in which he found that acetylating choline immensely increased its depressor activity, but didn't go any further with the analysis of that activity. Hunt supposed that it was entirely due to a weakening of the heart's action. $\mathrm{He}$ had been studying extracts of the suprarenal gland, estimating the amount of choline which they contained, and had found that they had a much stronger depressor action than could be attributed to the amount of choline which he could extract. I have very little doubt that the extra activity with which he was concerned was really due to the presence of the widely distributed histamine, the existence and action of which were not known at the time. Hunt, however, rather curiously, thought that it might be due to some derivative of choline which he hadn't been able to isolate. And so he got his friend Taveau to make a number of choline derivatives. The easy ones to make were the esters, and among these they easily picked out the acetic ester, acetyl-choline, as the one having a very intense depressor activity. In later years Hunt examined whole ranges of choline esters, and never found another one as intense in its depressor activity as acetyl-choline. At that time I read rather widely in physiological, pharmacological and medical literature, and I had a fairly retentive memory; but this particular item, which I had obviously noted at the time, had sunk into a subconscious layer of my memory, and I'd practically forgotten about it.

Then, about 1913, I was interrupted in the course of some other work which interested me. I was working then in a laboratory supported by industry, the Wellcome Laboratories, and I was interrupted by the arrival of an extract of ergot from the factory, with the request that I would test it, to see if it was suitable for clinical use. I thought this a nuisance, but I knew by experience that, if I postponed action, it would only make it worse, that I should get a series of reminders and things would pile up. So I said to my technician, "Bring along a cat and I'll do this at once." The cat was anesthetized and arrangements made for recording its arterial blood pressure in the conventional way, and I injected the customary dose of one cubic centimeter of this extract in the vein. And the cat's heart stopped dead. I thought, "Oh, clumsy fellow, you've injected a bubble of air into the circulation, and it's got into the coronary arteries, and that's that." I was turning away, to hang up my laboratory coat in disgust, and thinking, "I shall have to do another one now," when, out of the corner of my eye, I saw that the cat's heart had begun to beat again; and, presently, the blood pressure was completely restored. I thought that I might as well try it again; so I gave another cubic centi- meter, and exactly the same thing happened again. Then I began to take notice. I thought that I'd never seen an effect quite like this before, with an ergot extract, or any other. I had better see what this extract would do to other sorts of organs; and I tested it in the usual sort of routine, on isolated strips of rabbit's intestine, perfused frogs' hearts, and so on; and presently there began to be built up the picture of a general parasympathomimetic action. Then it occurred to me that ergot was a fungus, and after all, muscarine, the classical example of a substance having that sort of action, came from a fungus. So I called my young friend, Ewins, who was my chemical colleague at the time, and I said, "Ewins, I'm going to condemn that batch of ergot anyhow. Nobody could conscientiously allow it to go for human treatment; but we'll keep it for research. You go ahead and see if you can get anything like muscarine out of it." Presently Ewins got a pinch of platinum salt, a few milligrams, of the active thing. It had the action which I had noted, but it was a very much more evanescent action than that of muscarine; and I began to suspect that it couldn't be muscarine itself, and that idea was accentuated by some other experiments. I dissolved some of it, freed from the platinum salt, in Ringer's solution, and perfused a frog's heart with varying dilutions on a warm day; and in a few hours the activity began to diminish and finally disappeared. I went down to Ewins and said, "Look here, that's a very unstable thing; in a weakly alkaline solution it just vanishes."

Ewins said, "Sounds like an unstable ester of some sort, doesn't it."

I said, "It does."

He said, "We'll never identify it. We've only got those few milligrams, and we can't do anything with that amount; so we'll just have to leave it there."

And then, as I was getting into bed that night, suddenly, from some lower subconscious layer, there whirled up into my consciousness the memory of Reid Hunt and the acetic ester of choline. So I went down to the laboratory the next morning rather earlier than usual, from eagerness; and I caught Ewins and said, "Ewins, I wish you would get some choline and acetylate it for me. Let's have some acetyl-choline."

He said, "Oh, what's all this about?"

I said, "All right, my boy, you do it and we'll see."

And of course, there it was. And then, as I went on, there was a link-up with an earlier memory, and another friend, still my friend and colleague in other connections-T. R. Elliott. As long ago as 1904 when he was a postgraduate in Cambridge, before he had begun his 
medical qualification, he published a remarkable paper on the action of adrenaline. It is quite a physiological classic, and, even before that, Elliott had daringly put forward what seemed at that time an almost preposterous suggestion, namely, that the only way to explain the remarkable correspondence of the actions of adrenaline with those of the sympathetic nerves, an action which survived their degeneration, was to suppose that, when a sympathetic impulse reaches the ending of a nerve fibre, it liberates a small charge of adrenaline. And here we had a substance which imitated the actions of parasympathetic nerves even more accurately than adrenaline did those of sympathetic nerves. Of course, there were differences, the reason for which has again come to light quite recently. We know now that it isn't adrenaline, but noradrenaline which is thus liberated. Well, there was the new start of what has become a considerable story. Even Dr. Bronk has made interesting contact, I think, with the story, as it affects the function of acetyl-choline in transmitting impulses at synapses in peripheral ganglia.

Then as most of you know, another friend, Jack Eccles, formerly of Sydney and Dunedin, and now at Canberra, who had been the most truculent critic and opponent of any possibility of chemical transmission at voluntary myoneural synapses or at those in ganglia, suddenly, and for reasons which would never have made me think of chemical transmission, has now extended the conception to transmission at synapses in the central nervous system; and I expect that he will prove to be right. But I know very little about that, that's a matter for experts like Dr. Adrian. In any case this accident nearly forty years ago, the result of a request to test an extract of ergot, which I thought a nuisance, is still having some consequences which I find interesting; and I think that, on the whole, I take more pleasure and satisfaction just now in the thought of that particular experiment, than of any other.

\section{Bernardo Houssay, M.D., Nobel Prize Winner in Medicine, Buenos Aires}

It is difficult for me to say which of the many investigations I have undertaken with hundreds of associates in the course of forty-six years of laboratory work in physiology, in four different institutes, has given me most pleasure and satisfaction. So many have been satisfactory and I have enjoyed them all so much that I am faced by an embarras $d u$ choix. The greatest satisfaction and the highest reward are to be found in the work itself, in the endeavor to overcome difficulties encountered in the course of research, in the achievement of some inkling of the truth.

When I was a medical student I used to make notes of problems I thought worth while to investigate. When a student of physiology in 1907 I became interested in the hypophysis; the next year, 1908, I started to do experimental work on this gland, and forty-five years later I am still experimenting in order to find out more about the functions and significance of this fascinating leader of the endocrine orchestra.

I have been interested in many very different problems. I can almost say that if opportunity arises to work in some special field my interest will be simultaneously awakened. When I worked in the Public Health Laboratories from 1916 to 1919 one of my duties was the preparation of antivenom sera. I thus became interested in the venoms of snakes, spiders and scorpions and studied their biological effects.

In 192 I Lewis came to work with me on the adrenals and in I92I we had the satisfaction of proving that the adrenal cortex, not the medulla, was indispensable for life. At that time I worked with several associates on the factors regulating the secretion of adrenaline and more recently, of noradrenaline. At one time or another I have been interested in many aspects of the functions of each one of the endocrine glands.

Shortly after insulin was discovered, in 1922, Dr. Alfred Sordelli prepared insulin in Buenos Aires, and our group started to study its effects on the organism. Often the mail brought us published reports of results obtained by other workers on some of the problems we were investigating. It was, therefore, necessary to choose carefully fields which were not the object of study elsewhere. The action of insulin in relation to sympathetic and parasympathetic innervation and to the hormonal state of the organism was our field of choice. For this purpose the effects of insulin in animals deprived of the adrenals, or the thyroid or the hypophysis were observed. These glands had been the subject of research in my laboratory for several years, and at that time I had hypophysectomized dogs at my disposal. It was found that hypophysec- 


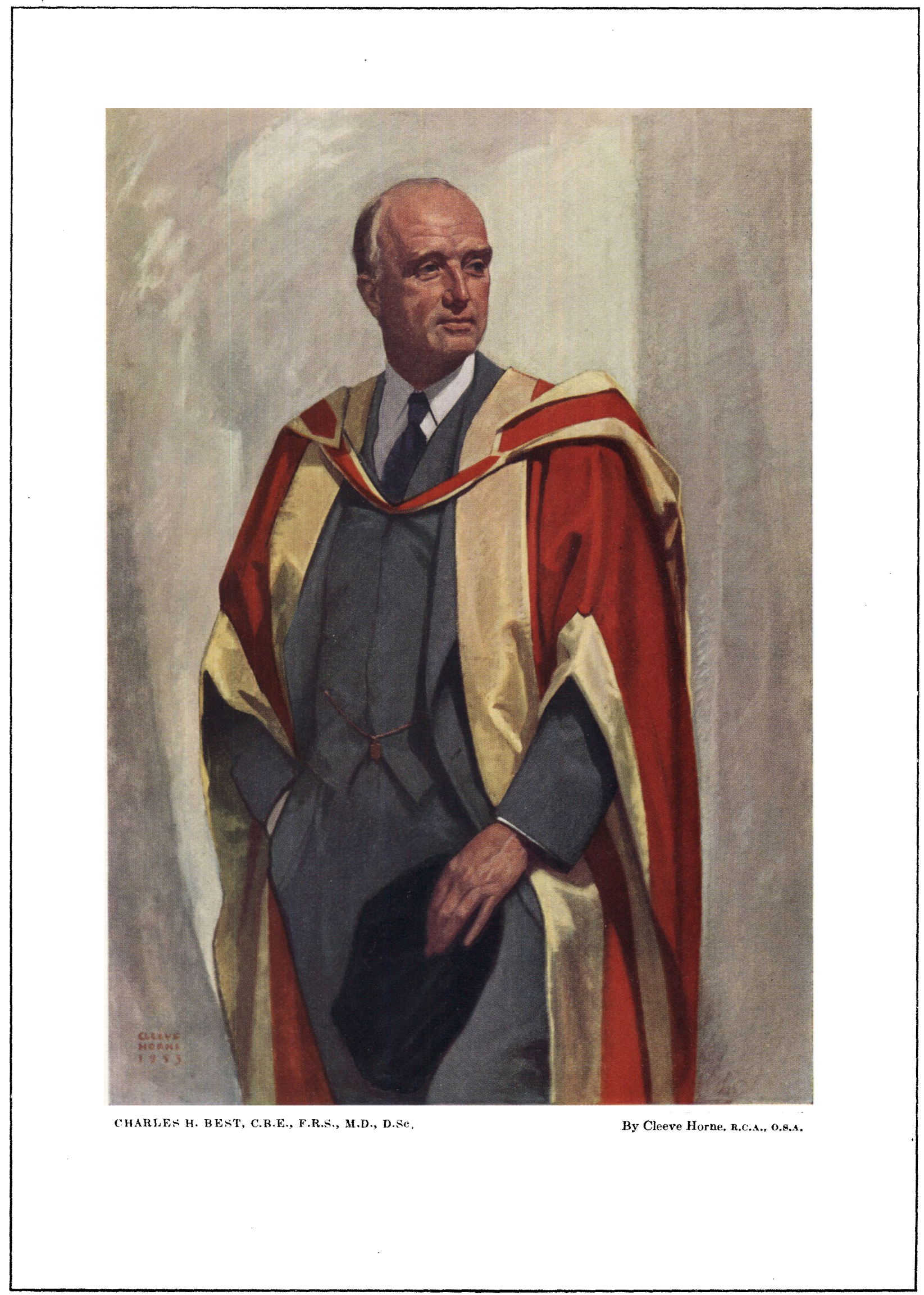


tomy considerably increased sensitiveness to insulin in dogs (with Magenta, 1924, 1927, 1929) and in toads (with Rietti and Mazzocco, 1924, I925).

In the toad it is easy to remove the pars distalis of the hypophysis leaving the pars nervosa intact. This operation increased sensitiveness to insulin. Working with Miss Potick in 1929, I was able to demonstrate that implantation of the pars distalis (the equivalent of the anterior lobe of mammals) abolished hypersensitiveness to insulin in hypophysectomized toads, and increased the resistance to insulin in normal animals. This fact was confirmed in dogs by Miss di Benedetto in 1932.

In 1929 working with Biasotti, I found that hypophysectomy diminished the severity of diabetes caused by pancreatectomy in dogs. Implantation of the pars distalis (anterior lobe of mammals) again increased the severity of diabetes. The diabetogenic effect of the hypophysis was thus demonstrated. The severe symptoms of pancreatic diabetes were due to two factors: (a) presence of a hypophyseal hormone, and (b) a lack of secretion of insulin. The diabetogenic effect of hypophyseal extracts in mammals was demonstrated in 1932 simultaneously in three laboratories: in Evans', in Marine's and in mine. In 1932, I was able to provoke permanent diabetes by hypophyseal treatment in dogs previously submitted to partial pancreatectomy. Young obtained this effect in dogs with intact pancreas in 1937.

A paper reporting the result of this work on the role of the hypophysis in diabetes was sent to the United States, but was rejected by several journals, until in I93 I it was published in Endocrinology. The results were soon confirmed and extended, but even in 1935 many of my colleagues in the United States remained unconvinced of the existence of a diabetogenic activity in anterohypophyseal extracts because they used preparations which rapidly lost their activity at room temperature. I was able to give an ample report of this work as Dunham Lecturer at Harvard in 1936, and at the celebration of the tercentenary of Harvard University I delivered a lecture on diabetes as a disturbance of endocrine regula- tion. Today I cannot help feeling great satisfaction when I see the idea that diabetes is a disturbance in the regulation of the hormonal equilibrium which controls carbohydrate metabolism and is universally accepted.

These investigations gave a demonstration of the existence of metabolic functions in the anterohypophysis, specially important in carbohydrate metabolism and the pathogenesis of diabetes. Carbohydrate metabolism was shown to be regulated by a hormonal equilibrium, the disturbance of which may cause diabetes, hyperinsulinism, etc.

These results were achieved by the work not of a single person but of many working in close association. In many cases I cannot say what was my personal contribution and what should be credited to my associates. Apart, however, from the great satisfaction of contributing to increase knowledge in a field which is important for the understanding of bodily functions in health and disease, this work served to train a host of young scientists and to stimulate the development of original scientific research in Latin America.

I have had many other satisfactions. I have been honored by my colleagues who have chosen me to be their fellow member in scientific societies, some of which for centuries have been famous throughout the world. I have also been honored by high distinctions such as the Nobel Prize for Medicine which was awarded to me in 1947, and here in Toronto by the Charles Mickle Fellowship. The greatest satisfactions I have felt do not have their source in these high honors, however much as I prize them. In times of trouble and trial I have seen many men, young and not so young, of great scientific and moral worth, to the scientific education of whom I had contributed, give signal proof of loyalty to those ideals of truth and freedom for which I have lived. Scientists from all over the world, many from North America, also have shown and continue to show their solidarity in many ways, but mostly by helping me and my associates to continue our scientific work. This has been my highest reward and gives me my greatest satisfaction.

\section{Elliott P. Joslin, M.D., Honorary President of the American Diabetes Association, Boston}

I know why I am here today. You may not realize it, but I am here because Dr. Best's father was a practitioner of medicine, and so Dr. Best wanted to honour practi- tioners of medicine everywhere by asking another to come and talk to you this morning.

Unquestionably the piling up of case after case of dia- 
betes has given me the greatest satisfaction, because by recording the facts of their completed life histories I proved to myself that aggressive, orthodox treatment of diabetes pays, and at the same time have shown my respect for what I have learned from Rollo, Bouchardat, Naunyn, Cantani, Petrén, von Noorden and a host of others. Do you realize that Rollo, who instigated treatment, published his book four years before my grandfather was born, in I80o? Not so long ago! You see how young the treatment of diabetes is! Each successive group of fatal cases has been a challenge to make the current group of living cases excel their predecessors. Such a challenge to oneself is harmless. No one is jealous of a doctor publishing his fatal cases.

I like to think how simply this all came about. Across the street from my boyhood home in Oxford, Massachusetts, lived the town historian, Mr. George F. Daniels. Without a college education he exemplified as high a type of scientific spirit as I have ever encountered. All his research was conducted unostentatiously, patiently and with scrupulous accuracy. He was started on his life's work by his father asking him, as he trudged back and forth to school, when he passed the site of the Indian Massacre of the Johnson family, to lay a stone on a pile to commemorate it. I can just remember that cairn of stones which he created and how as a little child I marched in the parade on a dusty summer's day in 1875 when the cairn was replaced with a monument. Subconsciously Mr. Daniels' cairn of stones and his faithful and meticulous history of Oxford influenced my whole life.

Today, I wish to show a report on a little less than a tenth of the cases coming under our observation, and to call attention to the fact that of 3,408 children, 2,806 are alive, as determined last week, and only 600 have died. I would call attention to the fact that of this group, there are only 23 that we have not traced in the last 56 years.
Of the group 428 are living over 25 years, I 3 I are living over 30 years and 9 over 35 years. Of course I am so interested in statistics I would like to say more about the rest, especially the pregnancy cases, after what you have heard from Prof. Hoet this morning, but I will forebear.

It is given to few among the world's two and a half billion souls to make a discovery like our friend, Charles $\mathrm{H}$. Best, who is honored here today. Perhaps in this century we could count the number on the fingers of our hands. Yet in contrast, each one of his students, even the humblest, the least gifted, if he should profit from that master word in medicine-WORK-uttered by that Canadian doctor, Osler, whom we all loved, could accomplish something of real value. That they should not be disheartened by the gap between teacher and pupil, I would add a phrase attributed to the German sculptor, Begas, "Jederman kann etwas thun was kein anderer Mensch kann." Each one can do something which no one else in the world can do. By the act of Charles $\mathrm{H}$. Best at the age of 23 years, ipso facto the status of all medical students was raised from that of student to investigator.

Not alone length of days, but life more abundantly is what we all seek for diabetics. Since the establishment of the Quarter Century Victory Medal for perfection of body, eyes and arteries, there have been 49 recipients, of whom only 18 are our own. There are so many others who have almost achieved perfection that we are establishing a new class-a blue ribbon class-in order to recognize their high endeavor.

To protect the future of diabetics, we hope to erect in Boston a Hospital Teaching Clinic in which ambulatory diabetics can return at much less than routine hospital costs, receive instruction, encouragement and such development of character that life and health, hitherto unrecorded for diabetics, will be attained.

\section{Wilder Penfield, M.D., Director of the Neurological Institute, McGill University, Montreal}

It's a great honour and pleasure for me (a surgical interloper) to be able to be here to enjoy these two days and I would like, before answering your question, to pay tribute from my University to this University, and on a personal basis, to the career of my friend, Charles Best. $I$ suppose that the discovery of insulin and its elabora- tion has been a romance, the like of which there are very few in medicine. It will always be a romance, told and re-told from the time of the inspiration that came to Banting, up to the time of the building of the Banting Institute, and now of the Best Institute. We are seeing, in a way, the end of that romance and the 
WILDER PENFIELD, M.D.

beginning of new work and new things and new discoveries which, we hope, will be equally important to mankind. Of course, when a clinician tries to add something to fundamental or basic research and knowledge, he is looked upon somewhat askance if he is a physician, but if he is a surgeon, he is looked upon askance by both the physician and the basic scientist. I think we should remind Dr. Best that he may have some need for clinicians in his new Institute and he should recognize, as Sir Henry Dale said yesterday, that his chief duty, as Director, is to oil the machinery of collaboration. I like that phrase, Sir Henry, I'm going to use it again. And I think that the Director of an Institute should be called an Oiler, and not a Director.

For a clinician, the greatest satisfaction in life, comes from his patients and his friendship with them. I am sure Sir Lionel will agree with me. On the other hand, satisfaction in scientific investigation is different. In scientific work, it seems to me, there are two forms of recompense. There is the thrill of pleasure that comes from a new observation that seems important, as Dr. Adrian described so beautifully in the wiggling of a line which shouldn't have wiggled. And there is the more permanent satisfaction that comes from eventual understanding. It is the thrill and excitement that an explorer must feel when he catches glimpses of a land that no one else knows, and there is the satisfaction that he must know when he occupies that land. The occupation can only be accomplished with a body of confreres and helpers.

In my professional career I've stood long hours at the operating table making careful records and using, as far as possible, methods of physiological precision. In hundreds of cases I have stimulated the exposed brain with a gentle electrical current while the patient lay conscious on the operating table. In each case, an effort was being made to find the abnormal area which was responsible for the patient's epileptic seizures and so to remove it and perhaps cure the seizures. I find it necessary to introduce such a preamble in order to illustrate the fact that in clinical medicine, one is never experimenting primarily, but only secondarily.

Once in a while during such an operation I have had the thrill and excitement of a new observation. I remember well the first production of vocalization. I was exploring the cortex with an electrode in that part of the precentral gyrus that lies between the area for movement of the contralateral thumb and the face, and when I set the electrode down on the gyrus the patient gave voice to a long-drawn cry like the cry of a newborn baby. It stopped instantly after the electrode was lifted. We were all startled, all in the operating room, including the patient. Each time the electrode was re-applied at that point, the result was the same. I realized then that man was different from other mammals in that he alone has a representation of vocalization in the cortex. Here was a mechanism which must contribute to his ability to speak.

I remember, too, when stimulation of the cortex deep within the relatively inaccessible fissure between the hemispheres produced movement and also vocalization, I guessed that there was another cortical area, a supplementary motor area. Then there was the day when an electrode caused a man to feel sensation in his arm, not in the well-known sensory area, but about six centimeters distant, just above the fissure of Sylvius, and the next stimulation, only about 2 centimeters lower, produced sensation in the leg. The man observed to me, "Those sensations were very peculiar ones." He found he wanted to move the limb in a certain direction but he was powerless to do so. I knew then that this must be the first demonstration in man of the second sensory area which Adrian had already described in animals.

Most unbelievable and most sobering of all were the psychical responses which came from time to time with stimulation of the superior and lateral surface of the temporal lobe. These were neither motor nor sensory but had to do with the mind. They appeared only rarely, with long months, sometimes years, between them. There was one woman who exclaimed that she heard an orchestra playing an air when the electrode was applied. The music stopped when the electrode was withdrawn and began again, twenty times over, when the electrode was re-applied to the same spot on the cortex. When I asked her to hum the air that she said she heard when I applied the electrode, she did so, verse and chorus. That music was passing through her conscious mind at the normal rate, and it was not a song which she knew completely at that time. It progressed much in the tempo of the orchestra, exactly as she had heard it playing years before. I realized that I was holding in my astonished hand the wand that would summon this particular recollection of past experience.

There have been other recollections, auditory, visual, or both, exactly as the patient experienced them and containing all the things to which he was paying attention at the time of the original occasion. Many of them had forgotten these experiences. There was a man who seemed to be laughing with his cousins, while his cousins were actually thousands of miles away in South Africa. There was a boy who saw men singing on a porch 
while he was walking along a country road; a mother who heard her son playing in the yard and was aware of the sound of passing automobiles. There was the man who saw the lighted sign of a dairy, and after that the neon sign of a bottling works. These events were summoned with a vividness as though they were occurring in the present time while the patient was still conscious of being in the operating room. They were having what Jackson described as "mental diplopia".

Such incidents draw a thrill of surprise and pleasure, but I've felt such thrills before, with equal pleasure, while demonstrating the parasympathetic nerve supply to the brain of a monkey, while impregnating with silver the perivascular nerves on small cerebral arteries, or drawing with the aid of the microscope the alterations in neuroglial cells and realizing that here were appearances that reflected the state of health of the brain as though in a cytological mirror. I have felt such fleeting satisfaction during the anxious labour of some complicated surgical procedure.

Years ago, I knew it also in the youthful background of the football field, during the rough and tumble of scrimmage with the roar of exciting sounds. Life seemed to hold nothing finer, there seemed to be no more worthwhile struggle, than the crossing of Yale's goal line. But one lasting truth I learned at that time, and that was that success comes with teamwork and satisfaction with common effort.

Professor Best has asked the question, "Which of your scientic investigations has given you the most satisfaction and pleasure?" and I have turned back to reconsider the different thrills that have come at different times, but those were not the most lasting satisfactions.
I think the most lasting satisfaction is that which comes during a review of clinical observations, at a time when you can stop considering the needs of each separate pa. tient, and when you can see things fitting together into a whole. It is the fitting into a general picture of these disjointed and occasional observations of a physiologicai type, particularly the psychical observations on memory, that have given me the greatest satisfaction.

It becomes apparent and it must be so, that there is in the two temporal cortices a recording mechanism, like a wire recording if you like, which is recording all those things to which we attend during our conscious life, from the time of the dawn of consciousness to the grave, and that the recording mechanism must pass through a central integrating system which integrates for the whole nervous system and projects it in some way to each temporal lobe, projects it so as to leave behind the pattern which can be activated by an electrode, to show in complete detail, all of those things to which a man attended at that time.

Nothing is lost, if one may judge from the occasional elements that can be activated electrically, nothing is lost in the mechanism of the nervous system. A great deal may seem to be lost to our voluntary attempt to re-construct. For a few seconds or a few minutes any of you can recall your experience as the electrode would recall it. You can close your eyes and see this room, but you will not be able to do so later. But the record is still there, and your memory recalls a generalization of and a reclassification of similar memories.

I think, Dr. Best, the greatest satisfaction I have had is in seeing these incidental observations on the cortex fall together in a reasonable way.

\section{Sir Lionel Whitby, Vice-Chancellor of the University of Cambridge}

It is often the function of the last batsman to have to gather very valuable runs, but those who have batted before me have done so so effectively that there is almost nothing for me to say in trying to answer this very difficult question posed by Charles Best. However, I am glad to say that I have had a most happy and active life, an extremely varied one which has thrown me into wars as a combatant and non-combatant, into the palaces of kings and into all sorts of situations, and I have had therefore some difficulty in picking out from that varied experience that which I think has given me the most satisfaction. Sir Henry Dale has said that there are so many aspects of satisfaction, that of happiness with colleagues, that of friends which one has made, and so on, and it is quite certain that one period of my life to which reference was made yesterday, (that of the last war) made for me so many friends that I often regard that time as having given me the most satisfaction and happiness. 
However, there was a certain period of nearly five years in my life in which my main interests were in therapeutic experiments and I will choose an incident from this period because it is slightly romantic, it shows that one has occasionally to exercise imagination, and it shows that it isn't always hard work which leads to a result, that in fact there is something to be said for the social side of life, including good living and enjoyment.

It was a relatively short five-year period of my life and out of this I was spun, as was said yesterday, to an assignment for war purposes, and to which I have therefore never had an opportunity to return. But soon after Domagk's discovery of prontosil I became interested in trying to extend it for the purpose of treating pneumon. ia. As Sir Henry has hinted, I was at that time associated with a delightful and very able chemist, Dr. Ewins, of Messrs. Ray and Baker (he had moved from Wellcome) and it was his part of the work to synthesize new compounds, as it was mine to test these biologically. We had a good deal of discussion over the years as to which compounds would be most likely to yield a successful result, but it wasn't easy to get a lead. But we eventually came to the conclusion that alterations at one end of the sulfonamide molecule were likely to be more productive than alterations at the other end. That particular observation eventually proved to be true and was exploited. But it was heartbreaking work. One never seemed to get anything much more active than sulfonamide itself against the infection known as the "Captain of the Men of Death".

However, in the summer of 1936 there was in England an International Serological Conference which I had attended, and which had its annual banquet to which we were all summoned as the final social event. After this banquet I emerged from the Trocadero Restaurant soon after midnight and instead of taking a taxi home I took it to the laboratory. Now I ought to say that experiments of the type which we were then doing were made on batches of mice, and it was an advantage to have an assistant to hold the mice, otherwise there might be damage to the operator from a bite. The experiment consisted of feeding the mice by stomach tube, a delicate operation, since the stomach tube was made of metal and there was a danger of perforating the esopnagus of the animal. I proceeded to the laboratory, looked at the mice, and then fed them with my own hand. The score was about even. That is, I got two bites, and I perforated two esophaguses. Nevertheless, from that batch of two dozen mice, on the next day for the first time there was a significant increase in the survival rate, as compared with all the substances which had hitherto been tested. There was, of course, a bit of luck, because in the batch was sulfapyridine. It was a very heartening result, but of course, it needed to be repeated. It was repeated, but with no effect whatsoever, and so one simply thought at first that the good result had been mere chance. There wasn't very much of the compound available, but after some two or three days it suddenly occurred to me that there was a distinct difference between the first batch of mice and all the other ones which had been tested. And that difference was, in fact, the same in the case of everybody who was working on the problem throughout the world, since everyone used roughly the same procedure. Our technique was to arrive at the laboratory at 8 in the morning, start the experiment, feed the mice and then give another feeding six hours later, and another before we went home about 6 in the evening. After that, the mice were left to see the night through. It occurred to me, of course, that the particular batch of mice, on account of the social event, had had an extra dose in the middle of the night, and that in fact proved to be the answer. To get an effect it was necessary to keep up the blood concentration by dosage in the night as well as in the day. That observation was, of course, eventually translated to the wards and those who have endured the discomforts of sulfapyridine treatment on account of an attack of pneumonia, will remember that they were awakened in the middle of the night in order to receive an administered dose.

Well, that fundamental therapeutic observation emanated from the chance of a dinner of the International Society of Serology in London. Perhaps I might say that, in retrospect, I have chosen this incident as giving me the greatest satisfaction, and I say this with all humility and diffidence, because out of that particular experience came calls to me to assist in the treatment of the pneumococcal infections of a patient, who was probably the most important person in the British Empire, during the past war.

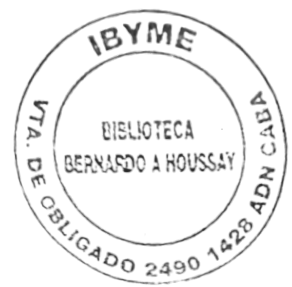

